\title{
INFLUENCE OF BOUNDARY CONDITIONS ON THE SOUTHERN HEMISPHERE ATMOSPHERIC CIRCULATION DURING THE LAST GLACIAL MAXIMUM
}

\author{
F. JUSTINO ${ }^{1}$, E. SOUZA², M. C. AMORIM ${ }^{1}$, P. L. SILVA DIAS ${ }^{3}$ e C. F. LEMOS ${ }^{1}$ \\ ${ }^{1}$ Universidade Federal de Viçosa, Departamento de Engenharia Agrícola \\ ${ }^{2}$ Universidade Federal de Campina Grande, Departamento de Ciências Atmosféricas \\ ${ }^{3}$ Laboratório Nacional de Computação Científica \\ fjustino@ufv.br
}

Received Novembro 2007 - Accepted Setembro 2008

\begin{abstract}
Based upon coupled climate simulations driven by present day and glacial boundary conditions, we demonstrate that although the ice sheet topography modifications during the glacial period are primarily placed in the Northern Hemisphere (NH), a climate simulation that employs the ICE-5G glacial topography delivers significantly enhanced climate anomalies in the Southern Hemisphere (SH) as well. These conditions, in association with climate anomalies produced by the modification of the atmospheric $\mathrm{CO}^{2}$ concentration characteristic of the Last Glacial Maximum (LGM) interval, are shown to be the primary forcing of the $\mathrm{SH}$ climate during this epoch. Climate anomalies up to $-6^{\circ} \mathrm{C}$ over the Antarctic region and $-4^{\circ} \mathrm{C}$ over South America are predicted to occur in respect to present day conditions. Accompanying the SH cooling in the LGM simulation there exists a remarkable reduction in the specific humidity, which in turn enforces the overall Southern Hemisphere cooling due to the weaker greenhouse capacity of the dry atmosphere.
\end{abstract}

Keywords: Last Glacial Maximum, Climate Changes, Baroclinic activity, $\mathrm{CO}^{2}$

RESUMO: INFLUÊNCIA DAS CONDIÇÕES DE FRONTEIRA NA CIRCULAÇÃO ATMOSFÉRICA DO HEMISFÉRIO SUL DURANTE O ÚLTIMO MÁXIMO GLACIAL.

Com base em simulações numéricas conduzidas com condições de fronteiras características dos períodos glaciais e atual, demonstra-se que embora as maiores anomalias da topografia da Terra no período glacial estejam no Hemisfério Norte, esta inclusão dos blocos de gelo leva a substanciais mudanças na circulação atmosférica austral para aquela época, indicando uma forte teleconexão inter-hemisférica. Em associação com a redução nos níveis de carbono atmosférico para 200 ppm, anomalias de temperatura de $-6^{\circ} \mathrm{C}$ em torno da região antártica, e $-4^{\circ} \mathrm{C}$ no continente sul-americano são simuladas para o último máximo glacial (UMG) em relação a condições atuais. Concomitantemente, o UMG é caracterizado por uma drástica redução na umidade específica, que por sua vez intensifica o esfriamento inicial devido à mais fraca capacidade de estufa da atmosfera mais seca.

Palavras chave: Último Máximo Glacial, Mudanças Climáticas, Baroclinia, $\mathrm{CO}^{2}$

\section{INTRODUCTION}

An important motivation to simulate past climatic conditions is that such experiments provide a unique opportunity to study the importance of climate feedbacks. They may help, therefore, to assess the validity of future-climate predictions. A thorough intercomparison of paleo-climate reconstructions based on the use of proxy data with model predictions for the same epoch is the first step towards an assessment of model performance under significantly different climate regimes.
Glacial climate has been subject of several complex modeling efforts focusing on atmospheric changes (e.g. Justino et al., 2005; Vettoretti et al., 2000; Broccoli and Manabe, 1987), and oceanic circulation changes (Peltier and Solheim, 2004; Shin et al., 2003; Hewitt et al., 2001). It has been demonstrated that the presence of Laurentide and Fennoscandia ice sheets in the Northern Hemisphere has both a topographic and a thermal effect which occur simultaneously and lead to a greater stationary eddy forcing of the zonal mean flow ( Justino et al, 2005; Shin et al, 2003; Vettoretti et al., 2000). The glacial inter- 
hemispheric teleconnection has also been explored by (Liu et al., 2005) and (Shin et al., 2002). They argued that the weakening of the glacial North Atlantic Thermohaline Circulation (NADW) was partially caused by the enhanced equatorward sea-ice transport due to stronger extratropical westerlies in the Southern Ocean during the LGM.

In addition, (Wainer et al., 2005) demonstrated that the combination of colder sea surface temperatures (SST) and wind anomalies led to a dryer LGM climate over South America. Similarly, ( Vizy and Cook, 2005), based on regional climate model simulations driven by four versions of LGM SST, found that these LGM simulations produced drier conditions over tropical South America. However, the extent of the aridity was found to be associated with the degree of cooling in the surrounding oceans, especially the tropical Atlantic.

Despite the increasing understanding of and interest in Earth's past climate, the impact of individual LGM boundary conditions on the SH climate, based on climate simulations conducted with global ocean-atmosphere-sea-ice models, has not been investigated in detail. Furthermore, oceanic dynamical changes during the LGM seem to be an important element in determining large-scale atmospheric flow patterns (Timmermann et al., 2004; Bush and Philander, 1998).

The goal of the present paper is to provide a preliminary investigation, which includes the ICE-5G model of ice sheet paleotopography (Peltier, 2004), on SH climate conditions.

a)
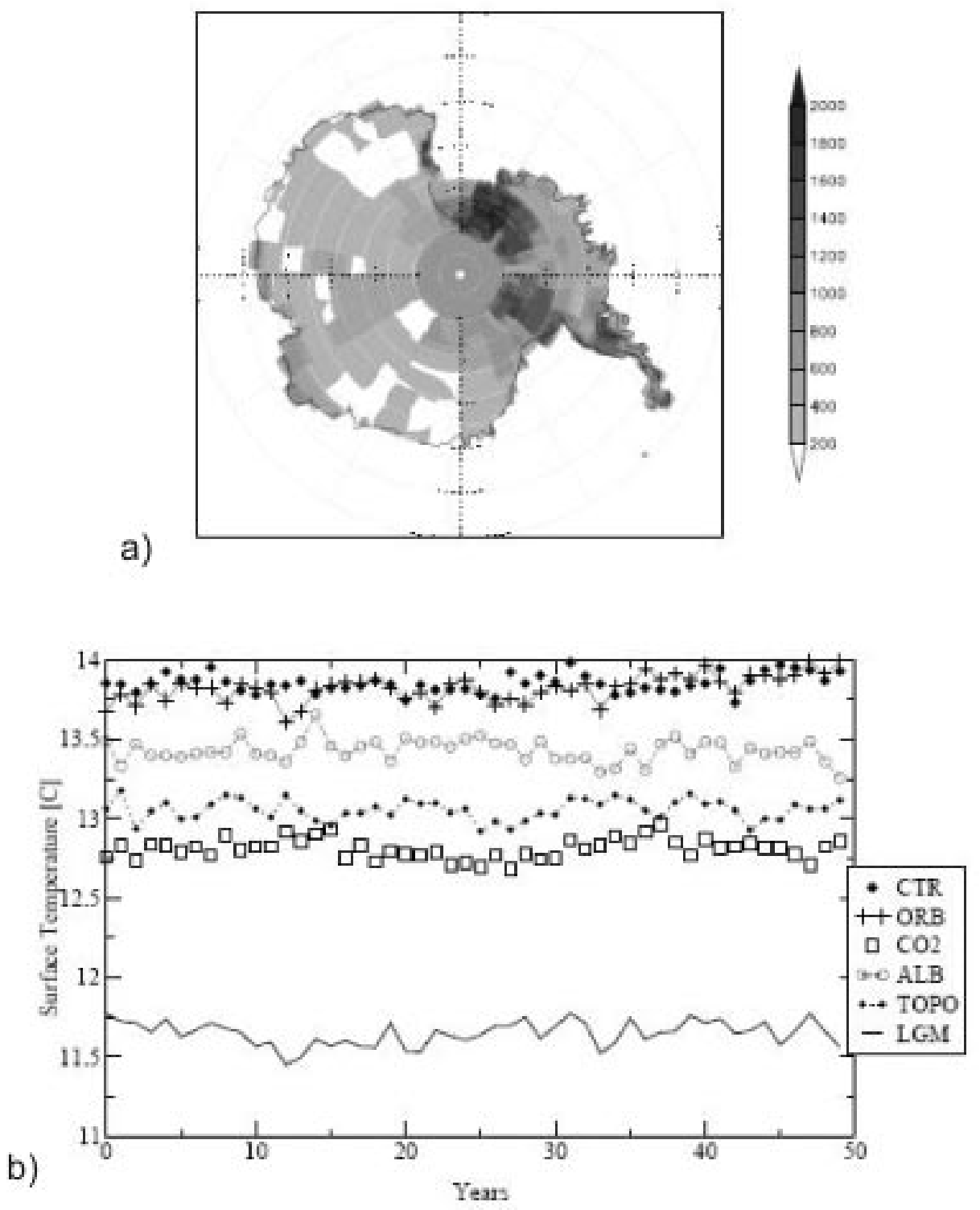

Figure 1 - a) Antarctic topography anomalies between ICE-5G and present day. b) Time evolution of annually area-averaged SH air temperature at $2 \mathrm{~m}\left({ }^{\circ} \mathrm{C}\right)$ 
The paper is organized as follows: Section 2 describes the coupled atmosphere-ocean-sea ice model, namely ECBiltClio, and the design of the LGM sensitivity experiments. In section 3 , we discuss the changes in radiative forcing, and the mean atmospheric and oceanic circulation changes due to the incorporation of the LGM boundary conditions. Additionally, section 3 provides a discussion of the glacial Antarctic Oscillation (AAO)/GSM. The paper concludes with a discussion and a summary of our main results.

\section{THE COUPLED CLIMATE MODEL AND THE DESIGN OF THE NUMERICAL EXPERIMENTS}

The atmospheric component ECBILT (Opsteegh et al., 1998) of our coupled model is a 3-layer model with a quasi-geostrophic adiabatic core and ageostrophic parametrizations (Marshall and Molteni, 1993), and a set of physical parametrizations for the hydrological cycle (Opsteegh et al., 1998), and a simplified radiation code. ECBilt uses

a)

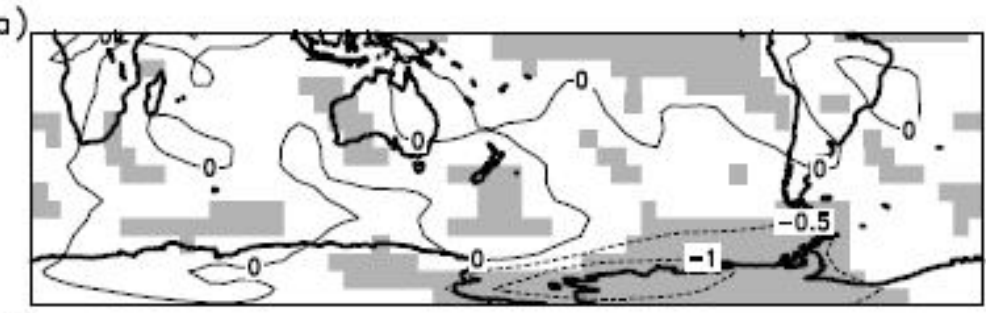

b)

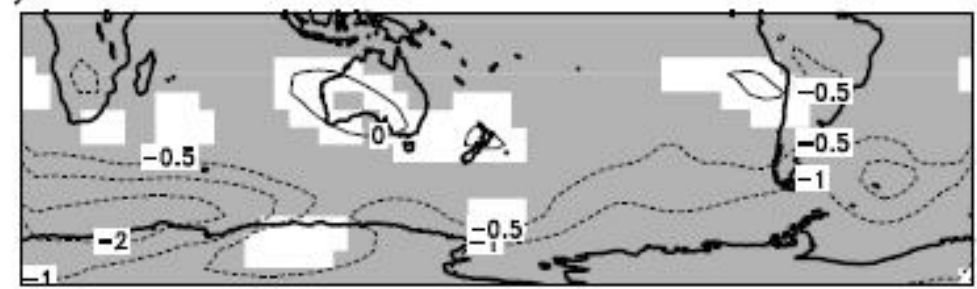

c)

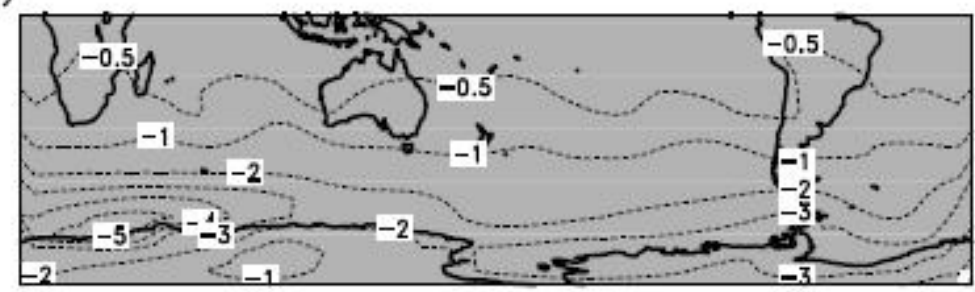

d)
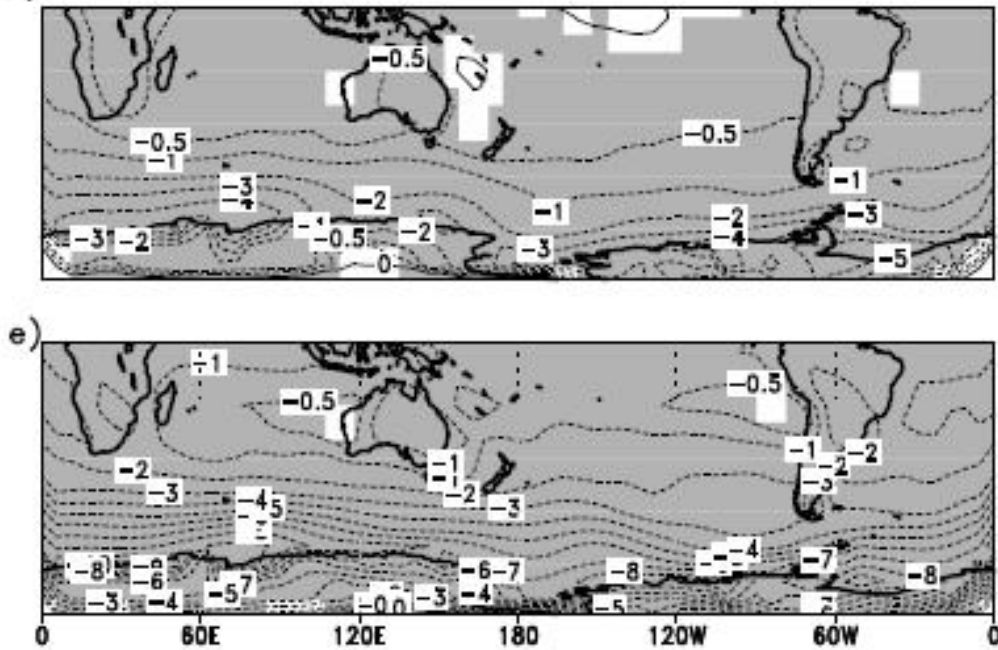

Figure 2 - Annual mean air temperature anomalies at $2 \mathrm{~m}\left[{ }^{\circ} \mathrm{C}\right]$ between ORB-MOD (a), ALB-MOD (b), CO2-MOD (c), TOPO-MOD (d) and LGMMOD (e) simulation. Shaded areas are statistically significant at $95 \%$ level based on calculations of student's t-test with 50 degrees of freedom. 
simplified parametrisations for the diabatic heating due to radiative fluxes. The diabatic heating is computed at 650 and 350 $\mathrm{hPa}$ from the various diabatic process associated with the long and shortwave radiation. A detailed description of the radiative code is provided by Justino (2004). ECBILT is a spectral model, run at a T21 triangular truncation which corresponds to an approximate resolution of 5.6o in both latitude and longitude. The coupled ocean-sea-ice model CLIO (Goosse et al., 1999) is based on the primitive equations and employs a free surface for the ocean component and thermodynamic/dynamic assumptions for the sea-ice component. A parametrization for vertical mixing is employed and constitutes a simplification of the Mellor and Yamada 2.5-level turbulence closure scheme (Mellor and Yamada, 1982). Furthermore, the ocean model CLIO includes mixing along isopycnals such as to capture the impact of mesoscale eddies on the transport (Gent and McWilliams, 1990) as well as the flow of dense water down topographic features (Campin and Goosse, 1999). The horizontal resolution of the CLIO model is $3^{\circ}$ and there are 20 unevenly spaced vertical levels in the ocean. The individual models are coupled through

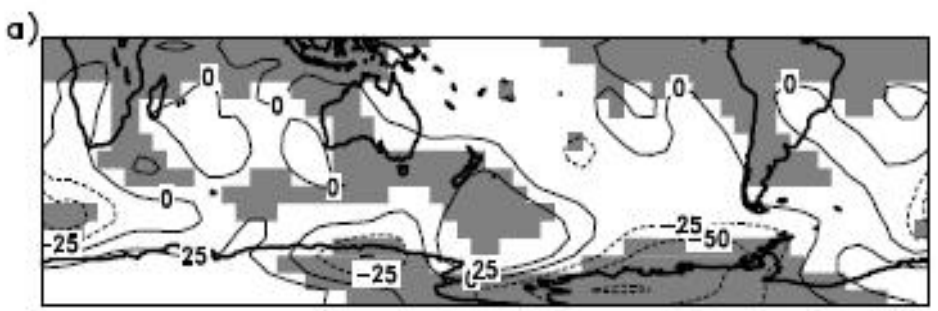

b)

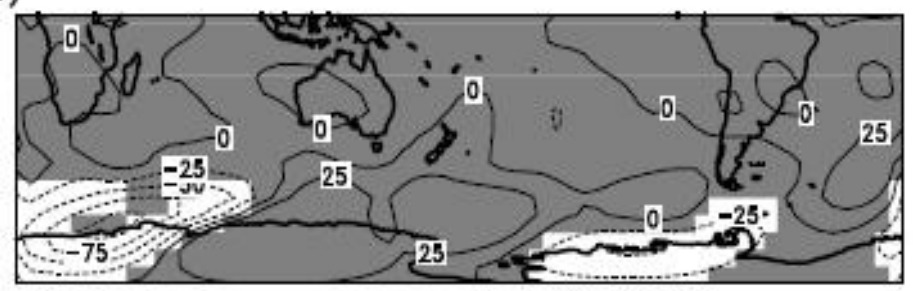

c)

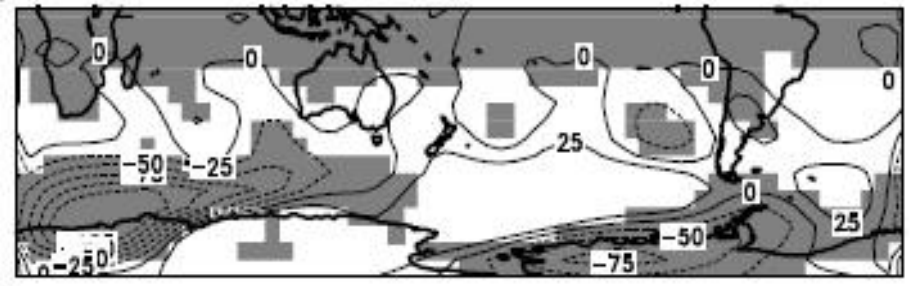

d)

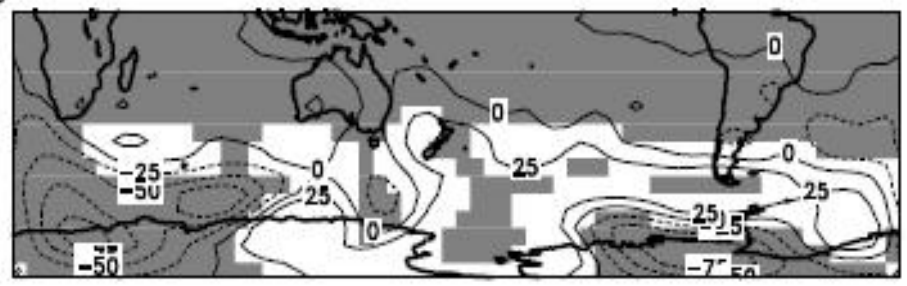

e)

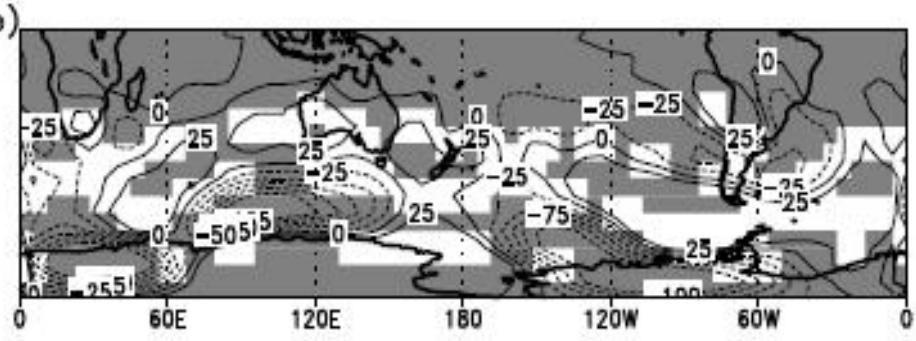

Figure 3 - The same as in Fig. 2 but for $\mathrm{Z} 200 \mathrm{~m}^{2} / \mathrm{s}^{2}$. 
exchanges of momentum, freshwater and heat and the simulations are performed using weak freshwater flux corrections so as to inhibit climate drift. As discussed by Selten (pers. comm.), the ECBILT-Clio model delivers climate anomalies due to increased greenhouse forcing in agreement with the NCAR-CCSM model; however, over the equatorial region ECBILT-Clio is colder then NCAR-CCSM by up to $1^{\circ} \mathrm{C}$.

In order to investigate climate anomalies induced by the incorporation of the LGM boundary conditions, we perform a series of sensitivity experiments. A 10000-yr-long preindustrial control simulation (MOD) is run. It employs an atmospheric $\mathrm{CO}^{2}$ concentration of $280 \mathrm{ppm}$ and present day albedo, vegetation, orbital forcing, and planetary topography boundary conditions. Five additional experiments were performed. In the first sensitivity experiment (ALB simulation) the surface albedo of the LGM ice sheets is prescribed. The albedo of the LGM is derived from a vegetation reconstruction (Crowley, 1995) where the deforested soils and plant cover are replaced by their respective albedo. Despite the uncertainties in the LGM land cover, Adam and Faure (1997) suggested that the rainforest, mainly placed in the $\mathrm{SH}$, covered one third or less of its present-day area. In addition, as a consequence of the changes from present-day sand desert and barren land to desert during the LGM, the albedo in southern Australia is reduced since the sand desert is clearer than the desert. It should be noted here that the albedo changes reflect the changes in the
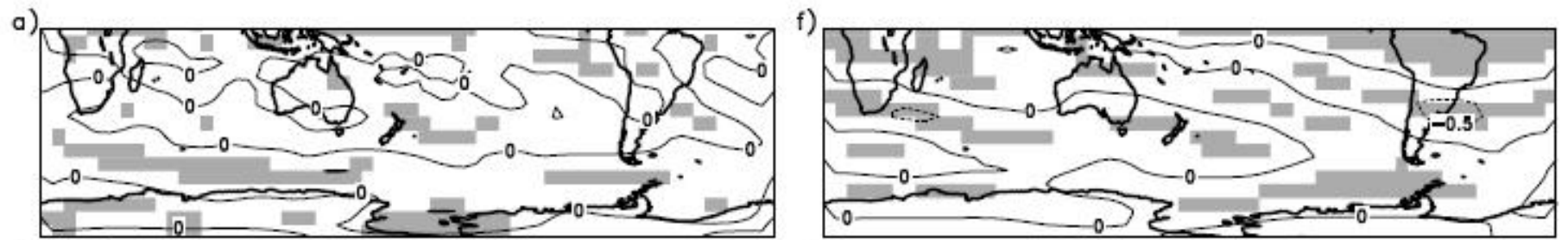

b)

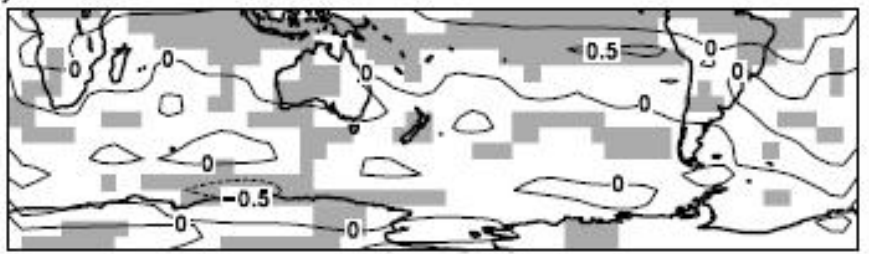

g)

c)

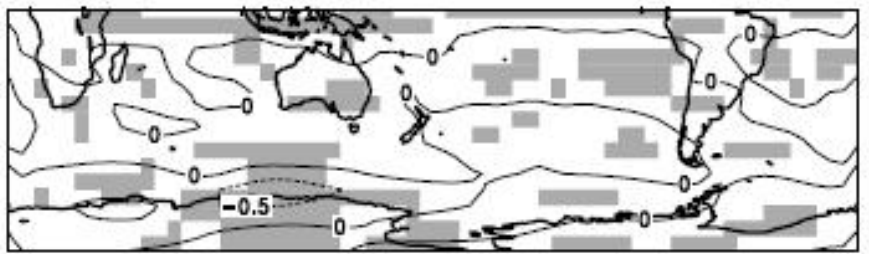

d)
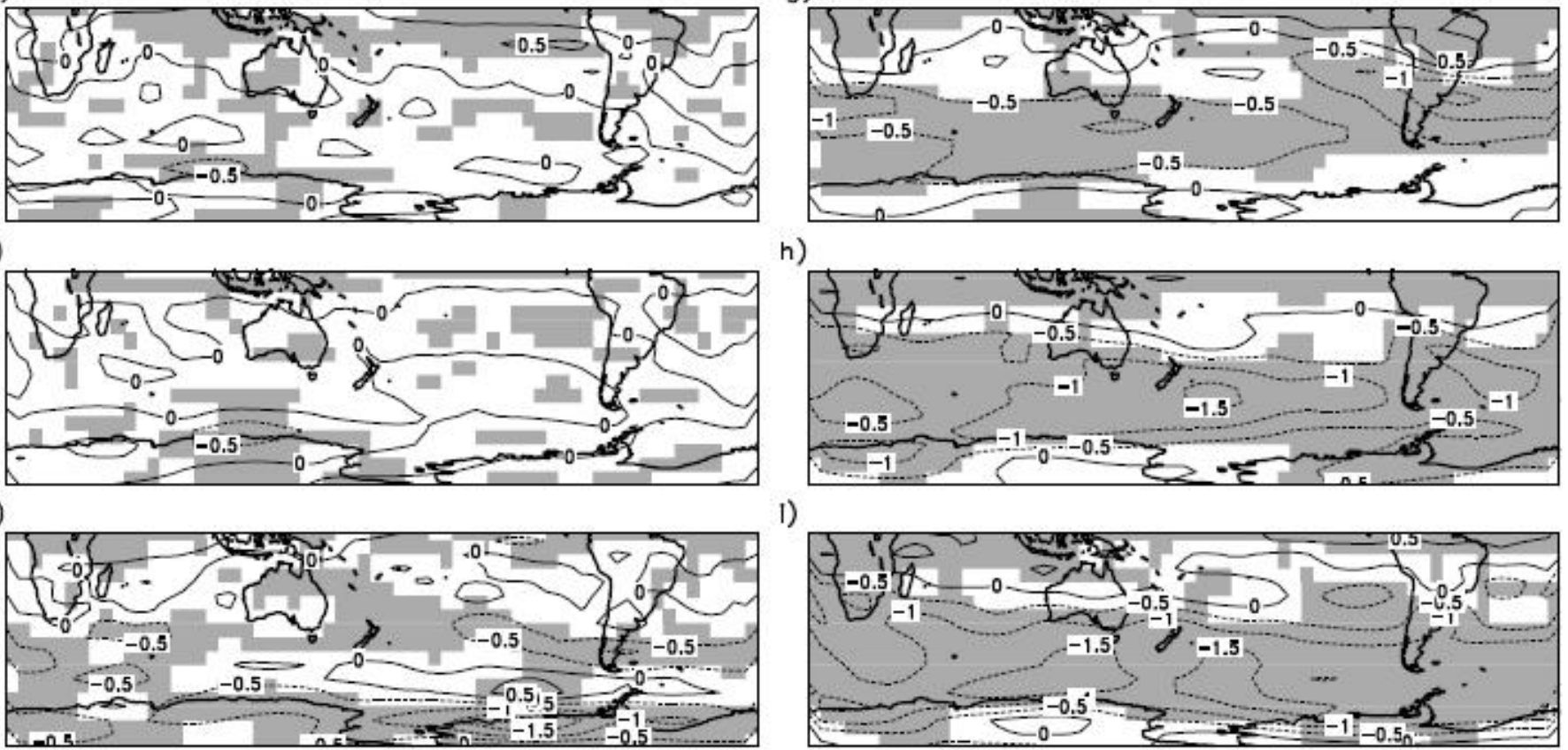

h)

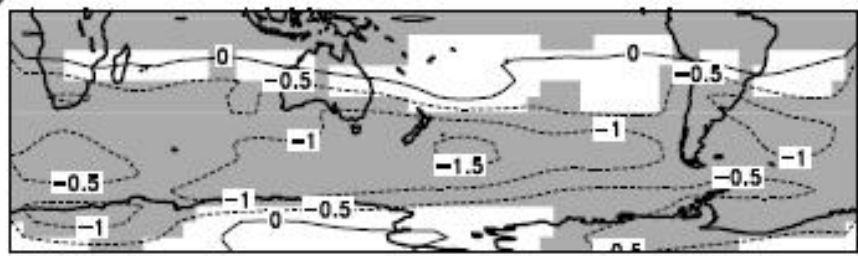

1)
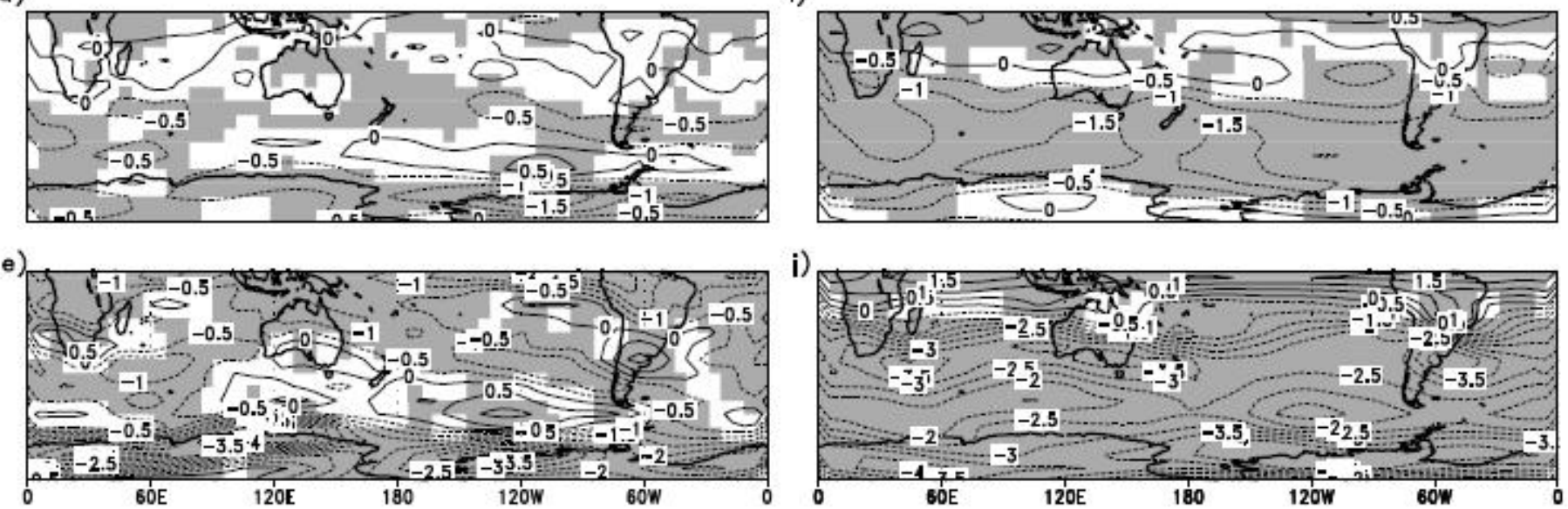

Figure 4 - Annual mean zonal wind anomalies at $800 \mathrm{hPa}$ between ORB-MOD (a); ALB-MOD (b); CO2-MOD (c); TOPO-MOD (d) and LGMMOD (e). Right panels (f,g,h,i,j) are the same as the left panels but at $200 \mathrm{hPa}$. Shaded areas are statistically significant at $95 \%$ level based on calculations of student's t-test with 50 degrees of freedom. 
vegetation color which are prescribed in ECBilt-Clio, rather than dynamically modeled. Moreover, the model does not compute evapotranspiration rate since the vegetation does not evolve dynamically. Unfortunately this avoids an in depth analysis of the link between the atmosphere and the biosphere. Therefore, our study cannot provide an investigation of the role of the glacial vegetation dynamics for the LGM climate.

The second simulation employs an atmospheric $\mathrm{CO}^{2}$ concentration of $200 \mathrm{ppm}\left(\mathrm{CO}^{2}\right.$ simulation). In the third simulation (TOPO simulation), the topographic features of the LGM ice sheets are prescribed using the ICE-5G reconstruction of Peltier (2004). Compared to present-day conditions, the inclusion of the ICE-5G topography creates a topographic barrier to atmospheric flow about 1500-m higher in the western Antarctic continent. It should be noted that changes in the TOPO simulation account only for the topographic characteristics of the ice sheet (elevation) and not for the albedo (Figure 1a). The orbital configuration of the LGM period (Berger, 1978) is taken into account in the fourth simulation (ORB simulation). Except for a slight reduction in the summer insolation caused by a reduced obliquity during the LGM changes of solar forcing due to LGM orbital parameters are very weak. Each sensitivity experiment consists of a 5000-yr-long simulation, starting from equilibrated conditions based on the MOD simulation. Our analysis focuses on the last 50 years, when the simulation has reached a new state of quasi-equilibrium for the variables under consideration. The fifth experiment, a 6000 -yr-long simulation (LGM), takes into account the most relevant boundary changes of the LGM: changes in topography, $\mathrm{CO}^{2}$ concentration, ice sheet albedo, and orbital forcing.

\section{RESULTS AND DISCUSSION}

\section{a. Changes of the circulation of the atmosphere}

Figure $1 \mathrm{~b}$ shows the $\mathrm{SH}$ annually area-averaged air temperature at $2 \mathrm{~m}(\mathrm{t} 2 \mathrm{~m})$ predicted by the sensitivity experiments and the MOD simulation. This reveals that the single modification of the orbital configuration, characteristic of the LGM interval, does not strongly affect the SH $2 \mathrm{~m}$ as compared with modern conditions. In contrast, the inclusion of the ice sheet albedo and topography, which are primarily Northern Hemisphere (NH) effects, induces a substantial SH surface cooling that can reach $0.4^{\circ} \mathrm{C}$ for albedo and $0.7^{\circ} \mathrm{C}$ for topography modifications.

Our results, however, pointed out that the SH glacial $\mathrm{t} 2 \mathrm{~m}$ was more strongly influenced by the reduction of the atmospheric $\mathrm{CO}^{2}$ concentration, which confirms the results of previous studies (e.g. Broccoli and Manabe, 1987; Rind, 1987). The $\mathrm{CO}^{2}$ simulation is up to $1^{\circ} \mathrm{C}$ colder than the MOD simulation (Figure 1b). The LGM simulation which incorporates the combined effect of the boundary conditions- delivers $t 2 \mathrm{~m}$ anomalies up to $2^{\circ} \mathrm{C}$ lower than in the MOD run (Figure $1 \mathrm{~b}$ ). This indicates that although the largest changes in boundary conditions are placed in the $\mathrm{NH}$, there also exists an interhemispheric thermal adjustment.

The spatial distribution of $\mathrm{t} 2 \mathrm{~m}$ anomalies between ALB, $\mathrm{CO}^{2}, \mathrm{ORB}, \mathrm{TOPO}, \mathrm{LGM}$ and MOD simulations are shown in Figure 2. The simulated SH mean $\mathrm{t} 2 \mathrm{~m}$ in the LGM takes approximately 3000 years to equilibrate. As a result of changes in the orbital parameters, temperature anomalies simulated by ORB show the maximum cooling over high latitudes decreasing in magnitude equatorward (Figure 2a). This extra-tropical cooling is associated with the well known temperature albedo feedback that is enhanced in the ORB simulation due to an increase of snow and sea-ice cover. Moreover, the negative shortwave radiation balance in high latitudes in summer leads to additional cooling through the reduction in the net radiation. In the tropical belt, temperature differences between ORB and MOD are relatively small and they are not statistically significant. Turning to $2 \mathrm{~m}$ anomalies between ALB and MOD (Figure $2 b$ ), it is evident that the largest changes over the continents originate from albedo changes in African and South American forests. Air temperature at $2 \mathrm{~m}$ drops by up to $1^{\circ} \mathrm{C}$ in northern South America due to the bright glacial vegetation (savannas) which, in turn, reduce the amount of absorbed solar radiation by about $15 \mathrm{~W} /$ $\mathrm{m} 2$. The opposite effect is observed in southwestern Australia, where the glacial albedo leads to local increase of solar radiation absorbed at the surface, resulting in positive temperature anomalies (Figure $2 b$ ). Compared to the MOD simulation, the $\mathrm{t} 2 \mathrm{~m}$ response to reduced $\mathrm{CO}^{2}$ concentration (Figure $2 \mathrm{c}$ ) is characterized by negative anomalies in high latitudes that can reach values up to $3^{\circ} \mathrm{C}$. This cooling is similar to that predicted by Broccoli and Manabe (1987), and is due essentially to the weaker greenhouse effect of the glacial atmosphere. Figure $2 d$ shows the t $2 \mathrm{~m}$ anomalies as a consequence of including the LGM ice-sheet topography. Negative temperature anomalies in the TOPO simulation are predominant around Antarctica as a result of a more extensive and thicker sea ice, and enhanced icesheet topography. It is important to note that the inclusion of the LGM ice-sheet topography of the ICE-5G model (Peltier, 1994) changes the height of the West Antarctica ice sheet. The land cooling, therefore, highlights the direct climate impact of the temperature lapse rate. In the tropics, the $t 2 \mathrm{~m}$ anomalies follow the SST changes. Some aspects of the SST changes are discussed in what follows. As a result of the inclusion of the four LGM boundary conditions, LGM simulation (Figure 2e) changes in $\mathrm{t} 2 \mathrm{~m}$ demonstrate that the maximum cooling occurs in the polar region. This glacial cooling is due primarily to the combined direct and indirect influences of the lapse rate in the low 
atmospheric $\mathrm{CO}^{2}$ concentration environment. Anomalies in the circumpolar region follow, in general, the changes in the glacial topography and, in particular, the enhanced topographic height in West Antarctica. In addition, the radiative cooling associated with a dryer atmosphere further enhances the polar cooling. In the tropics, however, the simulated temperature changes are primarily a result of the ocean dynamics. Nevertheless the dry atmosphere characteristic of the LGM interval reduces the back scattering of longwave radiation providing another source for tropical cooling.

As discussed by Cook and Held (1988), glacial ice sheets increase the zonal asymmetries - stationary waves - of the atmospheric circulation. Furthermore, the other LGM boundary conditions affect the stationary waves through the diabatic forcing and vorticity flux anomalies. Indeed, stationary wave anomalies characteristics of LGM conditions are highly significant in the $\mathrm{NH}$. In the SH, the substantial changes in Z200 (geopotential height at $200 \mathrm{hPa}$ with the zonal mean removed) are confined to high latitudes (Figure 3). It is interesting to note that comparing the individual response of Z200 to the LGM boundary conditions reveals similarities among the simulations. For instance, negative $\mathrm{Z} 200$ anomalies are predicted in $\mathrm{CO}^{2}$ and TOPO experiments from mid latitudes in the central Pacific through the Ross Sea and Antarctic Peninsula. The LGM Z200 anomalies (Figure 3e) could be interpreted as a consequence of the linear superposition of the individual glacial forcings which in turn leads to a well defined and oriented southwest-northeast wave train. Comparison between Z200 and Z800 (geopotential height at $800 \mathrm{hPa}$ with the zonal mean removed, not shown), indicates that this wave train in the LGM simulation (Fig. 3e) is embedded in a highly-baroclinic glacial atmosphere, in the sense that a high pressure system in the lower troposphere is followed by a low pressure system in the upper levels, and vice-versa. One might note that this high pressure system is not the Bolivian high since it is located in a different position as determined by previous studies (e.g. Lenters and Cook, 1997; Silva Dias et al.,1983). One should note that the changes of topography in the central Andes between the MOD and LGM simulations are negligible. Therefore, the primary candidate to cause the anomalous Z200 distributions in the ALB and LGM simulations is the diabatic heating anomalies. The latent heat release is reduced in both simulations due to changes in the rainforest area (not shown).

These changes in the thermal structure of the atmosphere as well as the modification of the atmospheric-mass distribution, as detected by Z200 and Z800 patterns, lead to anomalous atmospheric flow in the upper troposphere in particular. Figure 4 shows the zonal wind anomalies between the LGM sensitivity experiments and the modern simulation (MOD). It will be noted that the incorporation of the orbital forcing, the atmospheric $\mathrm{CO}^{2}$ concentration, and the ice-sheet albedo characteristics of the LGM period does not result in substantial changes of the zonal wind in the lower troposphere. In contrast, the presence of the glacial West Antarctica ice sheet of the ICE-5G model (Peltier, (a) $\mathrm{ALB}$ - MOD

Eady growth at $500 \mathrm{hPa}$

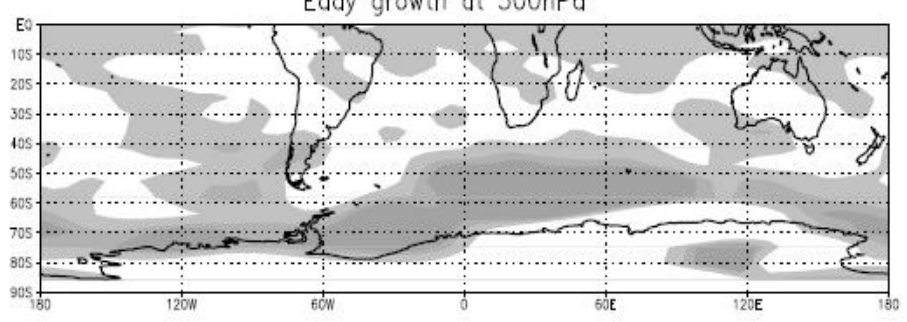

(c) TOPO - MOD

Eady growth at $500 \mathrm{hPa}$

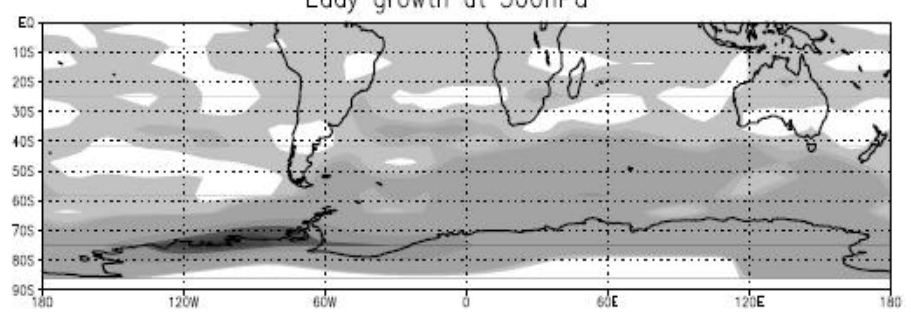

(b) $\mathrm{CO} 2-\mathrm{MOD}$

Eady growth at $500 \mathrm{hPa}$

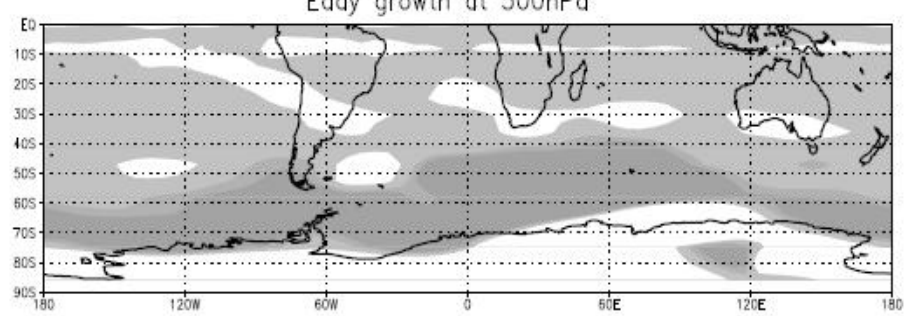

(d) LGM - MOD

Eady growth at $500 \mathrm{hPa}$

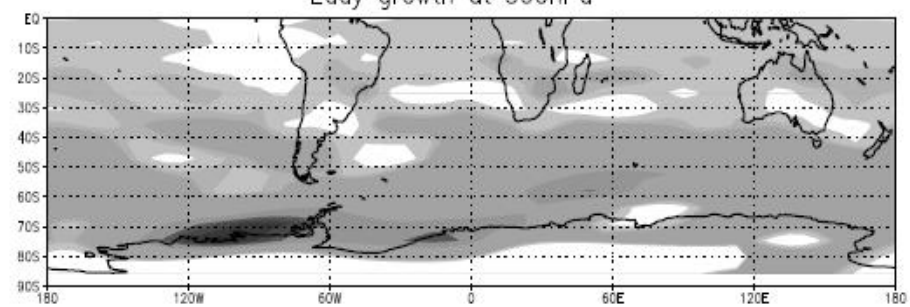

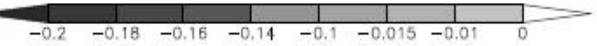

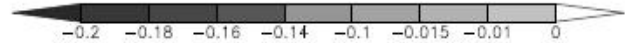

Figure 5 - Annual mean Eady growth rate anomalies (day-1). a) ALB-MOD; b) CO2 -MOD; c) TOPO-MOD and d) LGM-MOD simulations. Negative values are related to increased baroclinic instability. 
2004) leads to significant zonal wind anomalies (Figure 4d). This is highlighted over the Bellingshausen and Amundsen Seas and Marie Byrd Land (i.e. the Pacific/Indian Antarctic sector). Figure 4e shows that these wind anomalies are intensified due to the inclusion of all LGM forcings. This clearly causes changes of the equatorial and extratropical atmospheric flow. There exists a southward migration and an intensification of the mid-latitude westerlies and a strengthening of the trade winds. Hence, we conclude that the atmospheric $\mathrm{CO}^{2}$ concentration and the icesheet albedo play an important role in defining the nature of the glacial low-level zonal flow. Turning to the analysis of the upper-level flow, it is clear that the characteristic configuration of the LGM orbital forcing does not result in significant upperlevel wind anomalies (Figure 4f), as previously found for the $800 \mathrm{hPa}$ atmospheric level. Changes of surface albedo, on the other hand, reveal weaker westerly flow/jet stream (Figure 4g), as compared to present day conditions. Negative anomalies over the Southern part of Brazil fit nicely with the intensification of the high-pressure system along the subtropical eastern Pacific and with the presence of negative Z200 anomalies over the central-southeastern South American sector (see Figure 3b). As shown in Figures $4 \mathrm{~h}$ and $4 \mathrm{i}$, zonal wind anomalies due to modifications of atmospheric $\mathrm{CO}^{2}$ concentration and planetary topography are stronger than anomalies induced by changes in the ice-sheet albedo and in the orbital forcing. The TOPO and $\mathrm{CO}^{2}$ simulations reveal, moreover, a correspondence between the atmospheric $\mathrm{CO}^{2}$ concentration, the ice-sheet topography, and the magnitude of upper-level equatorial easterlies and midlatitude westerlies (Figures $4 \mathrm{~h}$ and $4 \mathrm{i}$ ). These wind patterns are also reproduced by the LGM simulation (Figure $4 \mathrm{j}$ ). It is not

a)

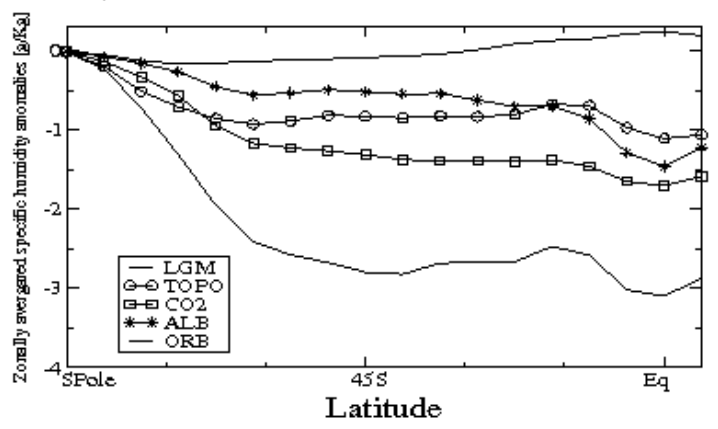

b) Precipitation Anom. $[\mathrm{cm} / \mathrm{yr}]$
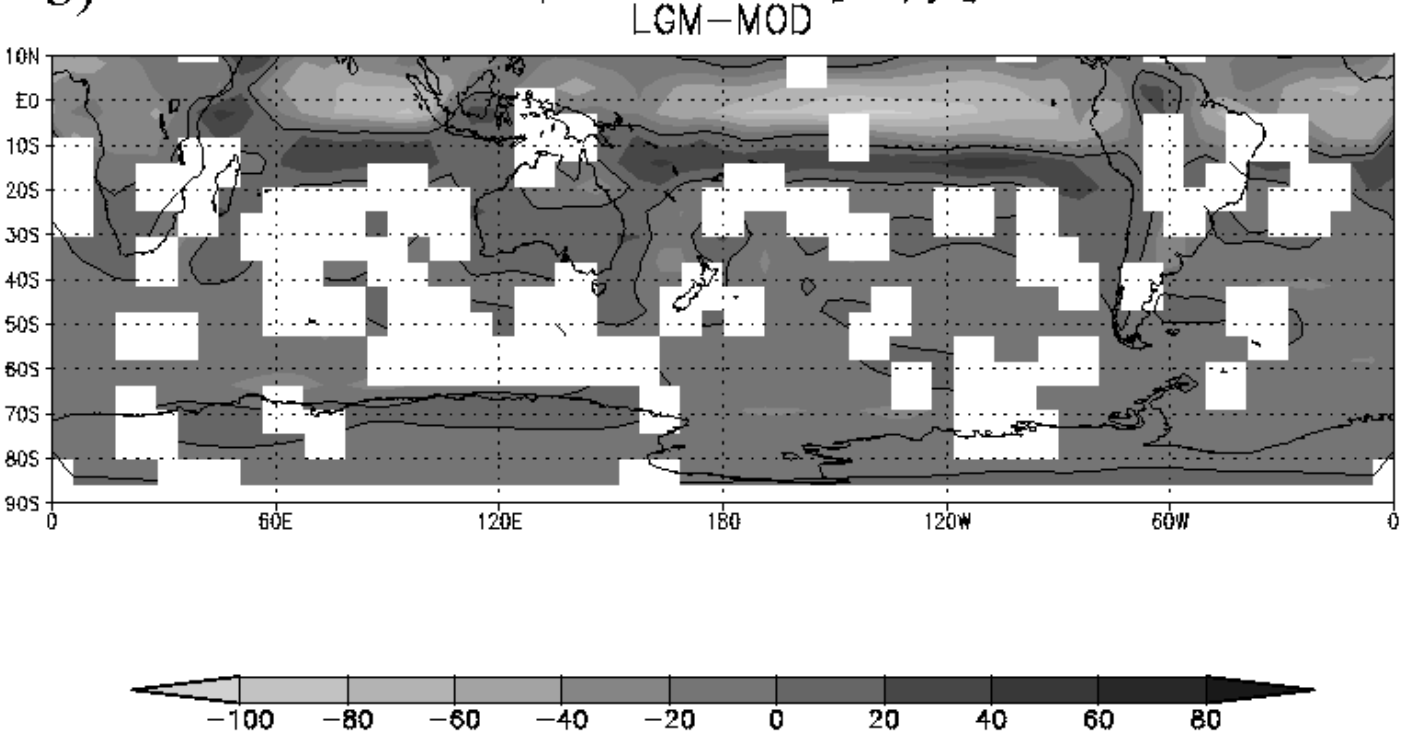

Figure 6 - a) Time averaged annual zonal mean specific humidity anomalies with respect to MOD in the different sensitivity experiments (g/kg); b) Precipitation anomalies between LGM and MOD simulations ( $\mathrm{cm} / \mathrm{yr}$ ). Shaded areas are statistically significant at $95 \%$ level based on calculations of student's t-test with 50 degrees of freedom. The zero contour is indicated. 
clear whether intensified trade winds under LGM conditions are due to atmospheric processes occurring in the $\mathrm{NH}$ or are mainly associated with the SH climate dynamics. However, the stronger equatorial winds in the TOPO simulation as compared to the $\mathrm{CO}^{2}$ simulation may reveal that the first assumption is more likely, as suggested by Timmermann et al. (2004). Moving forward, the impact of the LGM forcing upon the baroclinic structure of the atmosphere is analyzed. This may be approximately quantified in terms of the Eady growth rate (Lindzen and Farrell, 1980). This is a measure of the baroclinicity of the atmosphere and can be employed to quantify the potential for instability and cyclone growth. The Eady growth rate estimates baroclinic instability through the vertical wind shear and the static stability of the atmosphere. It is defined as $\delta_{\mathrm{BI}}=0.31 f / \mathrm{N}|\partial \mathrm{v} / \partial \mathrm{z}|$ where $f$ is the Coriolis parameter, $\mathrm{N}$ the Brunt-Vaisala frequency, $\mathrm{z}$ the upward vertical coordinate and $\mathrm{v}$ the horizontal wind. Figure 5 depicts the $\delta_{\mathrm{BI}}$ anomalies between the sensitivity experiments and modern conditions. Anomalies between the ORB and MOD simulation are negligible, thus they are not shown here. An inspection of Figure 5 clearly reveals that changes of climate conditions discussed previously are followed by higher Eady growth rate over the Antarctic circumpolar region in all sensitivity experiments as compared to the MOD simulation. The opposite is predicted to occur in mid latitudes in the ALB simulation, where positive anomalies of $\delta_{\mathrm{BI}}$ are more prominent in the western hemisphere (Figure 5a). Investigations of the static stability $(\mathrm{N})$ and vertical wind shear $(\partial \mathrm{v} / \partial \mathrm{z})$ (not shown), which drive the Eady growth rate, demonstrate that in mid latitudes there exists an increase of $\mathrm{N}$ that is accompanied by a weaker $\partial \mathrm{v} / \partial \mathrm{z}$. At high latitudes, however, strong vertical wind shear interacts with a much less stable atmosphere producing higher baroclinic instability. These features are found to be a characteristic of the $\mathrm{CO}^{2}$, TOPO and LGM simulations. Moreover, it can be demonstrated that, in general, $\delta_{\mathrm{BI}}$ anomalies induced by the topographic forcing is reproduced in the LGM simulation, a fact that usefully serves to highlight the dominant role of the Antarctica ice sheet. Investigations of $\mathrm{N}$ and $\partial \mathrm{v} / \partial \mathrm{z}$ may shed some light upon the climate impact of a possible reduction of the height of the Antarctic ice sheet due to its melting in a higher atmospheric $\mathrm{CO}^{2}$ - concentration environment. One can speculate that a lower ice sheet is perhaps associated with a more stable atmosphere and a weaker zonal-wind shear. This in turn may reduce the snowfall due to a weaker baroclinic instability destabilizing the ice-sheet mass balance. Obviously more studies are needed to investigate this issue in depth.

\section{b. Changes of Precipitation and Moisture}

It might be expected that changes of the thermal and dynamical structure of the glacial atmosphere would be associated with substantial changes in tropospheric moisture availability, and in the precipitation regimes as compared to present-day conditions. Indeed, as shown in Figure 6a, there exists a remarkable reduction in the specific humidity integrated from the surface to $500 \mathrm{hPa}$ in the LGM simulation. It is interesting to note that the reduction of the atmospheric $\mathrm{CO}^{2}$ concentration is responsible for the driest climate among the sensitivity experiments, whereas modifications of the orbital forcing do not lead to large changes of the specific humidity (Figure 6a). The link between changes in $\mathrm{CO}^{2}$ and the reduction in the specific humidity is primary associated with the induced oceanic cooling in the $\mathrm{CO}^{2}$ experiment and consequently lower evaporation rates. Turning to the changes in precipitation (Figure 6b), it is clear that the LGM climate is characterized by a reduction in precipitation in most of the tropics and extra tropics. In the equatorial region, the inter-tropical convergence zone (ITCZ) is shifted southward, which produces extremely dry conditions between $10^{\circ} \mathrm{N}$ and $10^{\circ} \mathrm{S}$. This is very likely associated with negative SST anomalies in the equatorial Pacific which resemble a permanent La Niña state. This result agrees with previous analyses based on derived proxy climate reconstructions (Martínez et al., 2003), that inferred a colder equatorial Pacific for the LGM period, as compared to modern conditions. Areas with positive precipitation anomalies are predominant between $10^{\circ} \mathrm{S}$ and $20^{\circ} \mathrm{S}$, in the South American west coast, and in southern Australia. Comparison with lake-level anomalies [(Kohfeld and Harrison, 2000), not shown] reveals that the simulated precipitation is in good agreement with the proxies, in particular in the equatorial Pacific. The simulation and the paleo-reconstruction also show good agreement over southern South America and equatorial Africa. There do exist, however, apparent discrepancies between model results and paleoceanographic reconstructions of tropical Pacific climate, as discussed by Rosenthal and Broccoli (2004).

\section{CONCLUDING REMARKS}

Based upon coupled climate simulations subject to present-day and Last Glacial Maximum conditions, we have investigated the individual impact of including LGM boundary conditions on the Southern Hemisphere climate. Our analyses provide evidence that the incorporation of the LGM ice sheets and changes in the atmospheric $\mathrm{CO}^{2}$ concentration play the most important role in generating $\mathrm{SH}$ atmosphericcirculation anomalies during the LGM. This impact of the ice-sheet topography was not anticipated since the primary modification of Earth's topography is located in the Northern Hemisphere. When averaged globally, the change in $\mathrm{CO}^{2}$ concentration generates the largest cooling as compared to the changes resulting from the other boundary conditions. Similar 
result has been reported by previous studies (e.g. Hewitt and Mitchell, 1997; Broccoli and Manabe, 1987). Accompanying the SH cooling in the LGM simulation there exists a remarkable reduction in the precipitable water which, in turn, enforces the overall SH cooling due to the weaker greenhouse capacity of the dry atmosphere (Figure 6).

Substantial changes in the SH tropospheric circulation are found in response to LGM boundary conditions. An inspection of the climate produced in the sensitivity experiments demonstrates that stationary waves anomalies are more pronounced in high latitudes. Despite the prediction of different magnitude anomalies, these simulations exhibit stationary wave patterns with reasonable degrees of similarities (Figure 3). The total LGM response may, therefore, be interpreted as a consequence of the linear superposition of the individual glacial forcings. It has been found that the forcing associated with the glacial anomalous diabatic heating is associated with changes in the position and intensity of the high pressure system located over the southern part of Brazil. These modifications of the stationary wave pattern are associated with changes of zonal wind. Figure 4 shows that in the LGM simulation there exists an intensification and southward migration of the low-level midlatitude westerlies and a strengthening of the trade winds.

Some limitations of our modeling approach originate from the set-up of the atmospheric model, which is based on the quasi-geostrophic (QG) approximation and uses just three atmospheric layers. Strictly speaking, the QG assumption holds for low Rossby numbers and for small topographic gradients. Despite this theoretical limitation, we have found (not shown here) that the atmospheric response to tropical SST anomalies is qualitatively well captured. However, the amplitude of the response is diminished in comparison with high-resolution primitive equation models, which is mostly due to the low resolution of our model, rather than due to the QG assumption. Furthermore, we have found that the inclusion of topography leads to an improved atmospheric circulation and stationary and transient wave activity as compared to a simulation which neglects orographic forcing. Hence, practically the model can cope much better both with tropical and orographic forcing than the strict theoretical considerations suggest. Furthermore, the inclusion of the Laurentide ice sheet in a three layer atmosphere $(200,500,800 \mathrm{hPa})$ may be problematic. However, a comparison with other coupled LGM simulations reveals that our modeling results compare well with those obtained from primitive equation multi-layer models. As an example, our simulated stationary wave anomalies induced by LGM forcing are qualitatively and quantitatively very similar to those obtained by Kitoh et al. (2001). The same holds for the simulated SST structure. The upstream high and downstream topographic low features of the ice-sheets also reproduce well the findings by Rind (1987, Figure 22) and Broccoli and Manabe (1987). Moreover, the results of Shin et al. (2003) (their Figure 16b), show a near-surface wind response which is similar to ours, both qualitatively and quantitatively.

\section{REFERENCES}

ADANS J.M. \& FAURE H. Palaeovegetation maps of the Earth during the Last Glacial Maximum, and the early and mid Holocene an aid to archaeological research. Journal of Archaeological Science, v.24 p.623 - 647, 1997.

BERGER, A. A simple algorithm to compute long-term variations of daily and monthly insolation. Technical Report 18, Institut d'astronomique et de géophysique, Universite Catholique de Louvain, Louvain-la-Neuve, 1978.

BROCCOLI, A.; MANABE, S. The influence of continental ice, atmospheric $\mathrm{CO} 2$ and land albedo on the climate of the last glacial maximum. Climate Dynamics, v. 1, p. 87 - 99, 1987.

BUSH, A. B. G.; PHILANDER, S. G. H. The Role of OceanAtmosphere Interactions in Tropical Cooling During the Last Glacial Maximum. Science, v. 279, p. 1341-1344, 1998.

CAMPIN, J.; GOOSSE, H. A parameterization of dense overflow in large-scale ocean models in $\mathrm{z}$ coordinate. Tellus, v. 51A, p. 412-430, 1999.

COOK, K.; HELD, I. Stationary waves of the ice age climate. Journal Climate, v. 1, p. 807-819, 1988.

CROWLEY, T. Ice age terrestrial carbon changes revisited. Global Biogeochemical Cycles, v. 9, p. 377-389, 1995.

GENT, P.; MCWILLIAMS, J. Isopycnal mixing in ocean general circulation models. Journal of Physical Oceanography, v. 20, p. 150-155, 1990.

GOOSSE, H.; DELEERSNIJDER, E.; FICHEFET, T.; ENGLAND, M. Sensitivity of a global coupled ocean-sea ice model to the parameterization of vertical mixing. Journal Geophysical Research, v. 104(C6), p. 13681-13695, 1999.

HEWITT, C. D.; BROCCOLI, A.; MITCHELL, J.; STOUFFER, R. J. A coupled model of the last glacial maximum: was part of the North Atlantic relatively warm? Geophysical Research Letters, v. 28, p. 1571-1574. 2001.

HEWITT, C. D.; MITCHELL, J. F. B. Radiative forcing and response of a GCM to ice age boundary conditions: cloud feedback and climate sensitivity. Climate Dynamics, v. 13, p. 821-834, 1997.

JUSTINO, F. The influence of glacial boundary conditions on the climate system during the Last Glacial Maximum. PhD. Thesis. Univ. of Kiel. 2004

JUSTINO, F.; TIMMERMANN, A.; MERKEL, U.; SOUZA, E. Synoptic reorganisation of atmospheric flow during the Last Glacial Maximum. Journal Climate, v. 18, p. 2826-2846. 2005. 
KITOH, A.; MUKARAMI; S.; KOIDE, H. A simulation of the Last Glacial Maximum with a coupled atmosphere-ocean GCM. Geophysical Research Letters, v. 28, p. 2221-2224, 2001.

KOHFELD, K.; HARRISON, S. How well can we simulate past climates? Evaluating the models using palaeoenvironmental datasets. Quaternary Science Reviews, v. 19, p. 321-346, 2000.

LENTERS, J.; COOK, K. On the Origin of the Bolivian High and Related Circulation Features of the South American Climate. Journal of the Atmospheric Sciences, v. 54, p. 656-677, 1997.

LINDZEN, R.; FARRELL, B. A simple approximate result for maximum growth rate of baroclinic instabilities. Journal of the Atmospheric Sciences, v. 37, p. 1648-1654, 1980.

LIU, Z.; SHIN, S.; WEBB, R.; LEWIS, W; OTTO-BLIESNERA, B. Atmospheric $\mathrm{CO} 2$, glacial thermohaline and climate. Geophysical Research Letters, v. 32, L02706, doi: 10.1029/2004GL02192. 2005.

MARSHALL, J.; MOLTENI; F.: Toward a dynamic understanding of planetary-scale flow regimes. Journal of the Atmospheric Sciences, v. 50, p. 1792-1818, 1993.

MARTÍNEZ, I.; KEIGWIN, L.; BARROWS, T. T.; YOKOYAMA, Y.; SOUTHON, J. La Niña-like conditions in the eastern equatorial Pacific and a stronger Choco jet in the northern Andes during the last glaciation. Paleoceanography, v. 18, p. 11-1, doi: 10.1029/2002PA000877. 2003.

MELLOR, G.; YAMADA, T. Development of a turbulence closure model for geophysical fluid problems. Reviews of Geophysics and Space Physics, v. 20, p. 851-875. 1982.

OPSTEEGH, J., HAARSMA, R.; SELTEN, F. KATTENBERG, A. ECBILT: A dynamic alternative to mixed boundary conditions in ocean models. Tellus, v. 50A, p. 348-367, 1998.

PELTIER, W. Ice age paleotopography. Science, v. 265, 195-201. 1994.

PELTIER, W. Global glacial isostasy and the surface of the ice-age Earth: the ICE-5G(VM2) model and GRACE. Annual Review of Earth and Planetary Sciences, v. 32, p.111-149, 2004.

PELTIER, W.; SOLHEIM, L.: The climate of the Earth at Last Glacial Maximum: statistical equilibrium state and a mode of internal variability. Quaternary Science Reviews, v. 23, iss. 3-4 [SPECIAL ISSUE], p. 335-357, 2004.

RIND, D. Components of the ice age circulation. Journal Geophysical Research, v. 92, p. 4241-4281, 1987.

ROSENTHAL, Y.; BROCCOLI, A. J. In Search of Paleo-ENSO. Science, v. 304, p. 219-221, doi: 10.1126/science.1095435, 2004.

SHIN, S. I.; LIU, Z.; OTTO-BLIESNER, B.; BRADY, E.; KUTZBACH, J.; VAVRUS, S. Southern Ocean sea-ice control of the glacial North Atlantic thermohaline circulation. Geophysical Research Letters, v. 30, doi:10.1029/ 2002GL015513. 2003.

SHIN, S. I.; LIU, Z.; OTTO-BLIESNER, B.; BRADY, E. C.; KUTZBACH, J. E.; HARRISON, S. P. A simulation of the Last Glacial Maximum Climate using the NCAR CSM. Climate Dynamics, v. 20, Issue 2-3, p. 127-151, 2002.

SILVA DIAS, P. L.; SCHUBERT, W. H.; DEMARIA, M. Large-scale response of the tropical atmosphere to transient convection. Journal of Atmospheric Sciences, v. 40, Issue 11, p. 2689-2707, 1983.

TIMMERMANN, A.; JUSTINO, F.; JIN, F. -F.; GOOSSE, H. Surface temperature control in the North and tropical Pacific during the last glacial maximum. Climate Dynamics, v. 23, n. 3-4, p. 353-370(18), 2004.

VETTORETTI, G.; PELTIER, W. R.; MCFARLANE, N. A. Global water balance and atmospheric water vapour transport at Last Glacial Maximum: Climate simulations with the CCCma atmospheric general circulation model. Canadian Journal of Earth Sciences, v. 37, p. 695-723, 2000.

VIZY, E. K.; COOK, K. H. Evaluation of Last Glacial Maximum sea surface temperature reconstructions through their influence on South American climate. Journal Geophysical Research, v. 110, D11105, doi:10.1029/2004JD005415, 2005.

WAINER, I.; CLAUZET, G.; LEDRUR, M.-P. Last Glacial Maximum in South America: Paleoclimate proxies and model results. Geophysical Research Letters, v. 32, doi:10.1029/2004GL0212442, 2005. 